\title{
Efficacy of a Nasal Spray Containing lota-Carrageenan in the Postexposure Prophylaxis of COVID-19 in Hospital Personnel Dedicated to Patients Care with COVID-19 Disease
}

Juan Manuel Figueroa, (D) Mónica Edith Lombardo, ${ }^{2,3}$ Ariel Dogliotti, ${ }^{4}$ Luis Pedro Flynn, ${ }^{5}$ Robert Giugliano, ${ }^{6}$ Guido Simonelli, Ricardo Valentini, ${ }^{2}$ Agñel Ramos, ${ }^{8}$ Pablo Romano, ${ }^{9}$ Marcelo Marcote, ${ }^{10}$ Alicia Michelini, "' Alejandro Salvado, ${ }^{12}$ Emilio Sykora, ${ }^{13}$ Cecilia Kniz, ${ }^{14}$ Marcelo Kobelinsky, ${ }^{15}$ David Manuel Salzberg, (iD ${ }^{16}$ Diana Jerusalinsky, ${ }^{17}$ Osvaldo Uchitel ${ }^{18}$

'Sleep and Respiratory Research Center, Instituto de Ciencia y Tecnología Cesar Milstein, Ciudad Autónoma de Buenos Aires, Argentina; ${ }^{2}$ Clinical Research Unit, Hospital Universitario CEMIC, Ciudad Autónoma de Buenos Aires, Argentina; ${ }^{3}$ Scientific Direction, Nobeltri S.R.L, Ciudad Autónoma de Buenos Aires, Argentina; ${ }^{4}$ Department of Cardiology, Instituto Cardiovascular de Rosario, Rosario, Santa Fe, Argentina; ${ }^{5}$ Department of Infectology, Sanatorio de Niños de Rosario, Rosario, Santa Fe, Argentina; ${ }^{6}$ Division of Cardiovascular Medicine, Brigham and Women's Hospital, and Department of Medicine, Harvard Medical School, Boston, MA, USA; ${ }^{7}$ Département de Médecine, Université de Montréal and Centre d'études avancées en médecine du sommeil, Hôpital du Sacré-Coeur de Montréal, Montréal, Quebec, Canada; ${ }^{8}$ Intensive Care Department. Sanatorio Parque de Rosario, Rosario, Santa Fe, Argentina; ${ }^{9}$ Otolaryngology Department, Clínica y Maternidad Santa Isabel, Ciudad Autónoma de Buenos Aires, Argentina; ${ }^{10}$ Medical Direction Department, Hospital Interzonal de Agudos Pte. Perón, Avellaneda, Buenos Aires, Argentina;

"'Pulmonology Department, Hospital Pediátrico Avelino Castelán, Resistencia, Chaco, Argentina; ${ }_{12}$ Pulmonology Department, Hospital Británico de Buenos Aires, Ciudad Autónoma de Buenos Aires, Argentina; ${ }^{13}$ Department of Medicine, Clínica Monte Grande, Monte Grande, Buenos Aires, Argentina;

${ }^{14}$ Pulmonology Department, Hospital 4 de Junio Dr Ramón Carrillo, Chaco, Argentina; ${ }^{15}$ Medical Direction, Clínica Modelo De Morón, Morón, Provincia de Buenos Aires, Argentina; ${ }^{16}$ Department of Family Medicine, Hospital Gral. de Agudos Dr. Teodoro Alvarez, Ciudad Autónoma de Buenos Aires, Argentina; ${ }^{17}$ Cell Biology and Neurosciences Institute (IBCN), Buenos Aires University-CONICET, Ciudad Autónoma de Buenos Aires, Argentina; ${ }^{18}$ Institute of Physiology, Molecular Biology and Neurosciences, Buenos Aires University-CONICET, Ciudad

Autónoma de Buenos Aires, Argentina

Correspondence: Juan Manuel Figueroa Instituto de Ciencia y Tecnología Cesar Milstein, Ciudad Autónoma de Buenos Aires, Argentina

Email figuejuan@gmail.com
Background: Iota-Carrageenan (I-C) is a sulfate polysaccharide synthesized by red algae, with demonstrated antiviral activity and clinical efficacy as nasal spray in the treatment of common cold. In vitro, I-C inhibits SARS-CoV-2 infection in cell culture.

Research Question: Can a nasal spray with Iota-Carrageenan be useful in the prophylaxis of COVID-19 in health care workers managing patients with COVID-19 disease?

Study Design and Methods: This is a pilot pragmatic multicenter, randomized, doubleblind, placebo-controlled study assessing the use of a nasal spray containing I-C in the prophylaxis of COVID-19 in hospital personnel dedicated to care of COVID-19 patients. Clinically healthy physicians, nurses, kinesiologists and other health care providers managing patients hospitalized for COVID-19 were assigned in a 1:1 ratio to receive four daily doses of I-C spray or placebo for 21 days. The primary end point was clinical COVID-19, as confirmed by reverse transcriptase polymerase chain reaction testing, over a period of 21 days. The trial is registered at ClinicalTrials.gov (NCT04521322).

Results: A total of 394 individuals were randomly assigned to receive I-C or placebo. Both treatment groups had similar baseline characteristics. The incidence of COVID-19 differs significantly between subjects receiving the nasal spray with I-C (2 of 196 [1.0\%]) and those receiving placebo (10 of 198 [5.0\%]). Relative risk reduction: $79.8 \%$ (95\% CI 5.3 to 95.4 ; $\mathrm{p}=0.03$ ). Absolute risk reduction: $4 \%$ (95\% CI 0.6 to 7.4$)$.

Interpretation: In this pilot study a nasal spray with I-C showed significant efficacy in preventing COVID-19 in health care workers managing patients with COVID-19 disease.

Clinical Trials Registration: NCT04521322.

Keywords: COVID-19, prophylaxis, nasal, spray, hospital workers

\section{Introduction}

A novel coronavirus, severe acute respiratory syndrome coronavirus 2 (SARS-CoV -2), was first identified in December 2019 as the cause of a respiratory illness called Coronavirus disease 2019, or COVID-19. Current available evidence shows that COVID-19 virus (SARS-CoV-2) is transmitted between people through close contact and inhalation of droplets. Being in close contact with infected individuals is therefore a risk factor to contract COVID-19. Unvaccinated health care providers, who are in close contact with COVID-19 patients are therefore at an increased risk for COVID-19. This inevitably places unvaccinated health and other hospital workers 
at a high risk of infection. COVID-19 vaccine developments have shown high efficacy at preventing COVID$19,{ }^{1,2}$ and vaccination rate among healthcare workers in high income countries has grown steadily since the first quarter of $2020 .^{3-6}$ Nevertheless, vaccine production challenges, distribution delays and global vaccine access have once again highlighted global inequality. Developed nations are vaccinating their populations much faster than less developed countries. To date, less than $10 \%$ of the world population has received the complete schedule of any of the vaccines and another $10 \%$ has received only one dose of any of those vaccines requiring two doses. The distribution of vaccines shows great inequality: for example, the USA and the United Kingdom have vaccinated more than $50 \%$ of their population, while in Argentina and Colombia less than $10 \%$ of the population has been vaccinated. In furtherance, more than 60 countries have a vaccination rate below the world average. At least 17,000 health workers have died from COVID-19 over the last year, according to an analysis by Amnesty International, Public Services (https://www. amnesty.org/en/latest/news/2021/03/covid19-health-workerdeath-toll-rises-to-at-least-17000-as-organizations-call-forrapid-vaccine-rollout/). The need to develop additional lowcost interventions to mitigate the risk of contracting COVID-19 among unvaccinated healthcare providers is crucial for the global South, where vaccination rate among healthcare providers remains low. The existence of other prophylactic intervention against this disease is yet unknown.

Iota-Carrageenan - a sulfated polysaccharide found in some species of red seaweed (Chondrus crispus) - has demonstrated antiviral activity against respiratory and other viruses in cell culture and in animal models. ${ }^{7-10}$ IotaCarrageenan inhibits viruses due to its interaction with the surface of viral particles, thus preventing them from entering cells and trapping the viral particles released from the infected cells. $^{10-13}$ In vitro and in vivo studies have demonstrated the effectiveness of Iota-Carrageenan against several respiratory viruses such as Human Rhinovirus, influenza A and common cold Coronavirus. ${ }^{10-17}$ Carrageenan has been extensively used in food, cosmetic and pharmaceutical industries, and is on the FDA list of generally recognized as safe (GRAS) products for consumption (21 CFR 172.620). Carrageenan is contained in medical device nasal spray that have been approved in USA (FDA Medical Devices Databases Establishment Registration \& Device Listing D 441354). It has been approved as a medical device class IIa in Europe and is sold as an over-the-counter (OTC) product in Europe, Asia and Australia, as part of a variety of over-the-counter products addressing common cold and related diseases (https://www.carragelose.com/en/portfolio/launched-

products). In Argentina a nasal spray with carrageenan has been approved by regulatory authorities and has been available for use for more than 7 years (ANMAT disposition 5158-2013). The same spray is sold in many Latin American countries (Belice, Costa Rica, registro sanitario M-AR-17-00376, Ministerio de Salud de la República de Costa Rica), Guatemala (registro sanitario PF-51028-2020, Ministerio de Salud Pública y Asistencia Social de Guatemala), Honduras (registro sanitario M-21389, Secretaría de Estado en el Despacho de Salud del Gobierno de la República de Honduras), Panamá (registro sanitario 106976, Ministerio de Salud de la República de Panamá), Paraguay (registro sanitario 03686-01-DM Ministerio de Salud Pública y Bienestar Social de la República del Paraguay), República Dominicana (registro sanitario 2016-0815 Ministerio de Salud Pública y Asistencia Social de República Dominicana) and Uruguay (registro sanitario 44540, Ministerio de Salud Pública de la República Oriental del Uruguay), information provided by the Head of International Regulatory Affairs of Laboratorio Pablo Cassará S.R.L., manufacturer of the nasal spray in Argentina.

Since the primary site of infection and replication of most cold-causing viruses is the nasal mucosa, it has been hypothesized that early and targeted treatment of the nasal mucosa with Iota-Carrageenan might block viral entry and locally interferes with the propagation of viral replication.

Three randomized clinical trials (two in adults and one in children) that compared Iota-Carrageenan nasal spray with saline solution (placebo) revealed high efficacy, including significantly reduced cold symptoms, ${ }^{15}$ faster reduction of symptoms intensity ${ }^{16}$ and significant reduction of viral loads ${ }^{14-16}$ in the carrageenan group. Treatments were safe and well tolerated. ${ }^{15-17}$

Iota-Carrageenan has demonstrated antiviral activity against SARS-CoV-2 virus and SARS-CoV-2 Spike Pseudotyped Lentivirus (SSPL) in cell lines and in primary differentiated human airway epithelial cultures. ${ }^{18-20}$ In preprint results, dilutions of the nasal spray available in Latin America were effective in inhibiting SARS-CoV-2 infection in monkey kidney cell line (Vero) and human respiratory cell line (Calu-3). ${ }^{21,22}$

Given that the concentrations found to be active in vitro against SARS-CoV-2 may be easily achieved by 
the application of nasal sprays already sold in several countries $^{18}$ and that at the onset of the disease the virus is localized mainly in the nasal cavity and the nasopharynx, ${ }^{23}$ we hypothesized that a nasal spray with Iota-Carrageenan could potentially be used as postexposure and during exposure prophylaxis, to prevent COVID19 in health workers managing patients with COVID-19.

\section{Methods}

\section{Study Design and Participants}

We conducted a pilot pragmatic randomized, placebocontrolled study to determine whether a nasal spray with Iota-Carrageenan can prevent COVID-19 disease in healthcare workers managing COVID-19 patients. This study was carried out when vaccination plans were not yet implemented in Argentina. We randomly assigned participants in a 1:1 ratio to receive either Iota-Carrageenan or placebo. Trial enrollment began on July 24, 2020. Health and other hospital workers managing hospitalized patients with a positive polymerase-chain-reaction (PCR) assay for SARS-CoV-2, were eligible. This trial was carried out in ten hospitals in Argentina (Hospital Universitario CEMIC, Sanatorio Parque de Rosario, Clínica y Maternidad Santa Isabel, Hospital Interzonal de Agudos Pte. Perón, Hospital Pediátrico Avelino Castelán, Hospital Británico de Buenos Aires, Clínica Monte Grande, Hospital 4 de Junio Dr Ramón Carrillo, Clínica Modelo de Morón, Hospital Gral. de Agudos Dr. Teodoro Alvarez), in compliance with ICHGCP and according to the Declaration of Helsinki. It was approved by the institutional review board and the ethics committees of the participating centers (or a centralized committee as applicable) (Registrations: Comité de Ética del Centro de Educación Médica e Investigaciones ClínicasCEMIC 1322, Comité Hospitalario de Ética Hospital 4 de Junio 0035/20, Comité provincial de Bioética, Provincia de Santa Fé 963, Comité de Ética para Investigación Clínica Fundación Dr. J. R. Villavicencio 24-07-2020, Comité de Bioética HIGA "Eva Perón” 57/20, Comité de Ética del Hospital Británico de Buenos Aires 1080, Comité Hospitalario de Ética Hospital Dr Avelino Castelán 22072020, Comité de Ética del Hospital Gral. de Agudos Dr. Teodoro Alvarez 2706). Participants provided written consent prior to their participation.

We included physicians, nurses, kinesiologists and other hospital workers with no history of COVID-19 disease, who managed patients in a COVID-19 hot zone in the hospital, and were therefore daily exposed to patients with COVID-19. Participants were excluded if they (a) had worked in an area without patients with a recent diagnosis of COVID no longer than 24 hours, (b) they were younger than 18 years (c) participated in any other clinical trial of an experimental treatment for COVID-19, (d) did not have a cell phone for remote monitoring, (e) reported hypersensitivity or known allergy to any component of the product, or (f) were pregnant or lactating. Additionally, health workers under suspicion of COVID19, COVID-19 history or with COVID-19 antibodies found in a previous routine screening were deemed ineligible to participate in this study.

\section{Randomisation and Masking}

Randomisation occurred at the coordinator center. A permuted-block randomisation sequence was carried out using sized blocks of 8 . A research pharmacist sequentially assigned participants to either of the groups. The assignments were concealed from investigators and participants (double blind).

\section{Procedures}

The participants were recruited in person by the researcher in charge of the center. Inclusion and exclusion criteria were reviewed for each one of them and they signed the informed consent.

Participants were instructed to self-administer 1 puff $(0.10 \mathrm{~mL}=0.17 \mathrm{mg}$ of I-C) of trial medication to each nostril 4 times per day. Trial medication was either IotaCarrageenan nasal spray approved for use in many Latin American countries or placebo. Each individual received two vials. The inhaler bottles containing the active principle or placebo were identical and odorless. The formulations and placebos were prepared at Laboratorio Pablo Cassará S.R.L. (Argentina) under aseptic conditions. Carrageenan spray: Iota-Carrageenan 0.17\%, Sodium Chloride 0.9\%, pH 6.00-7.00, isotonic; in a HighDensity Polyethylene bottle, $10 \mathrm{~mL}$ content, with dosing pump $(100 \mu \mathrm{L})$ and Preservative-Free System. Both the active sprays and the placebos were provided free of charge by the manufacturer.

The determination of posology is based on several antecedents: the application of Iota-Carrageenan spray 3 times a day has shown efficacy in clinical trials carried out on other respiratory viruses in which the active in vitro concentrations are similar to the active concentrations against the SARS-CoV-2; on the other hand, it has been shown that the Iota-Carrageenan spray applied to the nasal 
mucosa remains on it for about 4 hours. ${ }^{24}$ Application four times a day results in a reasonable balance between the chance of efficacy and adherence to treatment.

Post-exposure prophylaxis (PEP) is a treatment that can stop an infection after the individual has been in close contact with the virus. Since the objective was to intervene during the incubation period (the mean, median and 95th percentile for incubation period of COVID-19 are around 6,5 and 13 days, respectively, ${ }^{25,26)}$ most of the research done or proposed on COVID-19 PEP followed up the participants within 14 days after trial enrollment. ${ }^{27-30}$ We followed our participants an extra week, since by the time the study was designed, the pandemic was just beginning in Argentina and it was yet unknown whether it would take any particular form of development. The duration of this follow-up differs from that of studies on treatments for the disease, which begin after diagnosis and are longer (28 or more days), since they aim to evaluate the last and more severe phases of the disease. ${ }^{31}$

Treatment was mandatory for 21 days. At days 14 and 21 participants had a face-to-face control visit that included a review of the volume of liquid remaining in the container in use. The participants were excluded if the residual volume in the container exceeded $20 \%$ of the amount expected to be present if the doses had been duly applied until that day.

Participants continued to adhere to handwashing, use of personal protective equipment, physical distancing and general guidelines in compliance with regulations from health authorities. Follow-up was measured at day 21.

\section{Outcomes}

The primary outcome was prespecified as symptomatic illness confirmed by detection of SARS-CoV-2 by reverse transcriptase-polymerase chain reaction (PCR) at a local testing facility (using a protocol-defined acceptable test). On a daily basis, in the afternoon, participants received via text message in their phones, a Google Form survey with a structured questionnaire including the symptoms that should be reported: Over the last 24 hours have you been in contact with a patient with a confirmed diagnosis of COVID-19? Over the last 24 hours have you had temperature higher than $37.5^{\circ} \mathrm{C}$ ? Over the last 24 hours have you had cough? Over the last 24 hours have you had a sore throat? Over the last 24 hours have you had muscle aches not consistent with knocks or exercise? Over the last 24 hours have you had a headache? Over the last 24 hours have you had diarrhea and/or vomiting? Over the last 24 hours have you experienced reduction or loss of taste? Over the last 24 hours have you experienced reduction or loss of smell?

The responses were reviewed every night and should any participant report symptoms, they were informed to the investigator in charge at the center. The head of the center was also informed of all the individuals who had not answered the daily questionnaire.

The investigator at the center evaluated whether the symptoms could be assigned to a cause other than COVID19 (for example, migraine in a patient with a history of such condition who had previously reported to the researcher that their headache was their usual manifestation).

Regarding those subjects who failed to answer the form, they were asked to do so in the morning, and to further report it to the investigator of the center.

Upon confirmation of suspicious symptoms of COVID-19, the participants were sent to undergo a nasopharyngeal swab with a PCR test for SARS-CoV-2 and were isolated on a preventive basis until the PCR result was available. Patients with positive PCR continued in isolation for management of their disease. PCR-negative individuals returned to their workplace 48 hours after their symptoms had disappeared. Participants with a negative PCR whose symptoms persisted for 48 hours after the first PCR, must undergo a new PCR.

The symptom questionnaire should not be submitted only in the case of participant with a confirmed positive PCR.

\section{Statistical Analysis}

We estimated that 200 participants should be enrolled in each group to give the trial approximately $80 \%$ power, at two-sided type I error rate of 5\%, to show that COVID-19 would be $50 \%$ lower in the active treatment group than in the placebo.

The strength of association was expressed as a relative risk reduction and its $95 \%$ confidence intervals $(95 \% \mathrm{CI})$. Proportions were compared with the chi-square test or Fisher's exact test, and the continuous quantitative variables with the Student's $t$-test. All analyses were conducted with Statistical Analysis Software SAS ${ }^{\circledR}$ version 9.4 (SAS Institute, Inc, Cary, North Carolina), according to the intention-to-treat principle, with two-sided type I error with an alpha of 0.05 .

\section{Results}

From July 24 to December 20, 2020, a total of 400 hospital workers were enrolled and randomized at 10 hospitals in Argentina. 
Six participants were excluded from the final analysis because they had symptoms suggestive of COVID-19 at the time of randomisation. Of the remaining 394 participants, 196 had been assigned to receive Iota-Carrageenan and 198 placebo.

Thirteen individuals in the Iota-Carrageenan group and 14 in the placebo group withdrew their consent before day 21 and did not provide information about their health status (6.8\%) (Figure 1). All the remaining participants answered the daily surveys and complied with at least $80 \%$ of the doses indicated for the study.

The mean age of participants was $38.5 \pm 9$ years, and $75.1 \%$ were female (Table 1).

Forty-three participants underwent a PCR test due to the presence of symptoms suggestive of COVID-19 (Table 2), 31 were negative ( $7.6 \%$ in the Iota-Carrageenan group and $8.6 \%$ in the placebo group; $p=0.8$ ).

Overall, new COVID-19 (symptomatic with confirmed PCR) developed in 12 of 394 participants (3.04\%) during the 21 days of follow-up (Table 2).
The incidence of COVID-19 differs significantly between subjects receiving the nasal spray with IotaCarrageenan (2 of 196 [1.0\%]) and those receiving placebo (10 of 198 [5.0\%]). Relative risk reduction: $79.8 \%$ ( $95 \%$ CI 5.3 to $95.4 ; \mathrm{p}=0.03$ ). Absolute risk reduction: $4 \%$ (95\% CI 0.6 to 7.4 ). The 2 individuals in the I-C arm began with symptoms on days 2 and 4 after randomisation. In contrast, in the placebo arm 2 individuals were symptomatic on days 4 and 8 and the rest developed symptoms 11 days after randomisation (Figure 2).

In the Iota-Carrageenan group and placebo group, $17.3 \%$ and $15.2 \%$, respectively, reported at least one adverse effect $(\mathrm{p}=0.5)$ Table 2 .

\section{Discussion}

The results of this study suggest that the Iota-Carrageenan nasal spray is safe and effective to prevent COVID-19 disease in hospital workers managing COVID-19 patients. In our study we identified a risk reduction around $80 \%$. The effect was obtained using the spray within the dosage

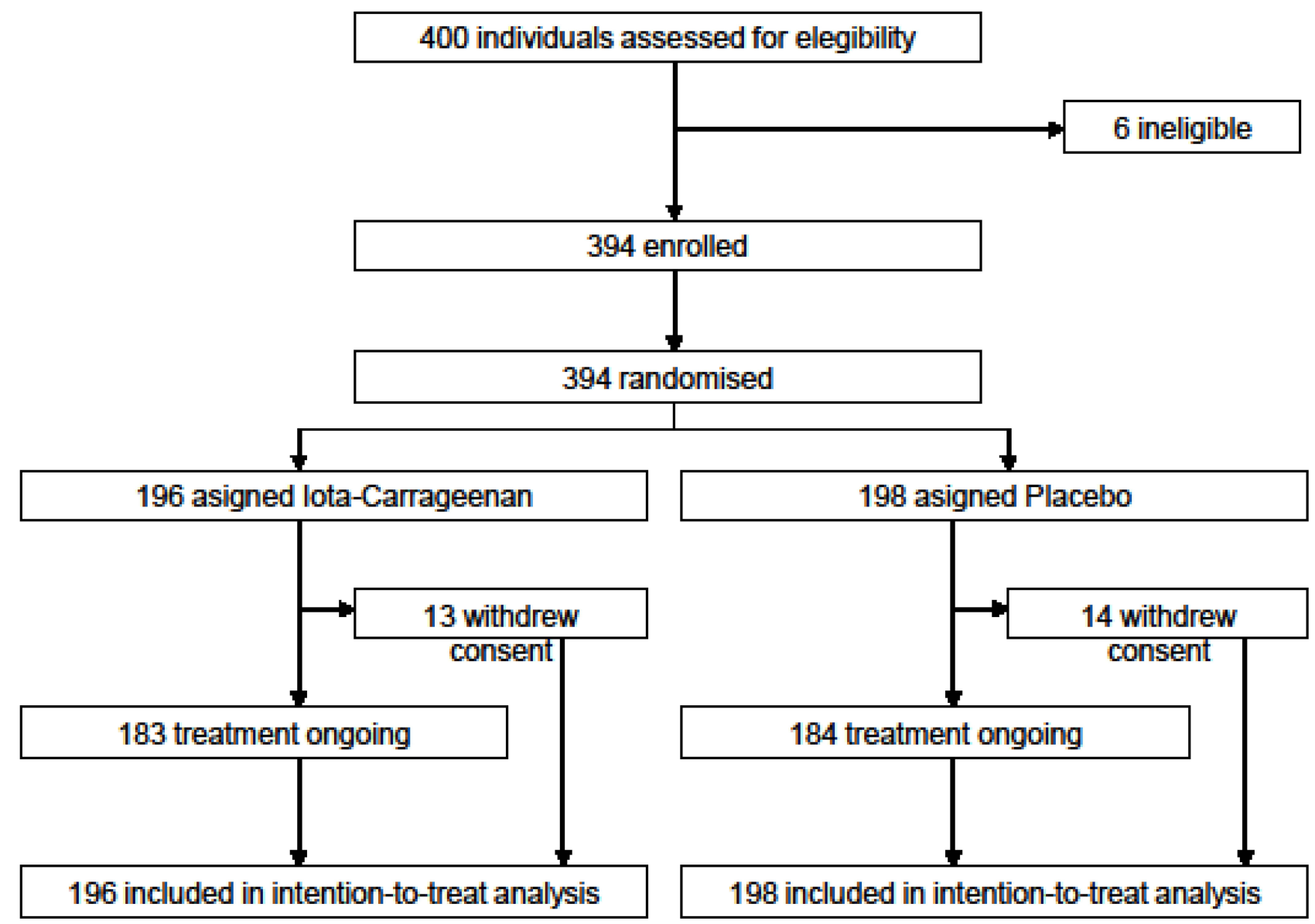

Figure I Study flowchart. 
Table I Baseline Characteristics of the Intention-to-Treat Population

\begin{tabular}{|c|c|c|c|}
\hline & $I-C(n=196)$ & Placebo $(n=198)$ & $p$ value \\
\hline \multicolumn{4}{|l|}{ Sex } \\
\hline Female & $|4|$ (71.9\%) & I55 (78.3\%) & 0.1 \\
\hline Male & 55 (28.1\%) & $43(21.7 \%)$ & \\
\hline Age, years & $38.3(10.1)$ & $38.8(9.2)$ & 0.8 \\
\hline \multicolumn{4}{|l|}{ Ethnic origin } \\
\hline White and latino & $196(100 \%)$ & 198 (100\%) & 1.0 \\
\hline Physicians & 97 (49.5\%) & 95 (48.0\%) & 0.8 \\
\hline Nurses & $50(25.5 \%)$ & $62(31.3 \%)$ & 0.2 \\
\hline Technicians & $24(I 2.2 \%)$ & $26(13.1 \%)$ & 0.8 \\
\hline Others medical providers & 22 (11.2\%) & $18(9.1 \%)$ & 0.5 \\
\hline \multicolumn{4}{|l|}{ Co-morbidities } \\
\hline No co-morbidities & I57 (80.1\%) & 147 (74.2\%) & 0.2 \\
\hline Chronic pulmonary disease & $6(3.0 \%)$ & 7 (3.5\%) & $1.0 *$ \\
\hline High blood pressure & $9(4.6 \%)$ & $10(5.1 \%)$ & 0.8 \\
\hline Obesity & 7 (3.6\%) & $13(6.6 \%)$ & 0.2 \\
\hline Severe obesity & $0(0 \%)$ & $0(0 \%)$ & \\
\hline Hypothyroidism & $12(6.1 \%)$ & 9 (4.5\%) & 0.5 \\
\hline Smoking & I (0.5\%) & $3(1.5 \%)$ & $0.6^{*}$ \\
\hline Type 2 diabetes mellitus & $0(0 \%)$ & I (0.5\%) & $1.0 *$ \\
\hline Cancer & $0(0 \%)$ & $0(0 \%)$ & \\
\hline Chronic kidney disease & $0(0 \%)$ & $0(0 \%)$ & \\
\hline Down syndrome & $0(0 \%)$ & $0(0 \%)$ & \\
\hline Heart disease & $0(0 \%)$ & $0(0 \%)$ & \\
\hline Inmunocompro-mised state & $0(0 \%)$ & $0(0 \%)$ & \\
\hline
\end{tabular}

Notes: Data are $\mathrm{n}(\%)$, mean (SD). *Fisher's exact test. Obesity (body mass index of $30 \mathrm{Kg} / \mathrm{m}^{2}$ or higher but $<40 \mathrm{~kg} / \mathrm{m}^{2}$ ).

Abbreviation: I-C, lota carrageenan.

Table 2 Findings

\begin{tabular}{|l|c|c|c|c|c|}
\hline & Participants (n=394) & I-C (n=196) & Placebo (n=198) & OR (95\% CI) & $\mathbf{P}$ value \\
\hline Primary outcome & $12(3.0 \%)$ & $2(1.0 \%)$ & $10(5.0 \%)$ & $0.19(0.05$ to 0.77$)$ & $0.03^{*}$ \\
\hline Death or hospitalization for any cause & $0(0 \%)$ & $0(0 \%)$ & $0(0 \%)$ & & \\
\hline Symptomatic negative PCR & $31 / 382(8.1 \%)$ & $15 / 197(7.6 \%)$ & $16 / 185(8.6 \%)$ & $0.87(0.42$ to 1.8$)$ & 0.7 \\
\hline Adverse effects & & & & \\
At least one adverse effect & $64(16.2 \%)$ & $34(17.3 \%)$ & $30(15.2 \%)$ & \\
Headache & $30(7.6 \%)$ & $17(8.7 \%)$ & $13(6.6 \%)$ & 0.5 \\
Rhinorrhea & $9(2.3 \%)$ & $3(1.5 \%)$ & $6(3.0 \%)$ & \\
Suspended for intolerance & $5(1.2 \%)$ & $2(1.0 \%)$ & $3(1.5 \%)$ & \\
\hline
\end{tabular}

Note: *Fisher's exact test.

Abbreviations: $\mathrm{Cl}$, confidence interval; I-C, lota-carrageenan; OR, odds ratio; PCR, reverse-transcriptase-polymerase-chain-reaction testing.

that is approved for use by the health authority. A small number of individuals presented adverse effects, with no difference between the group treated with I-C and the placebo group. Adverse effects were mild, which is consistent with that described in other clinical trials ${ }^{15-17}$ and in short, medium, and long-term toxicity studies conducted 


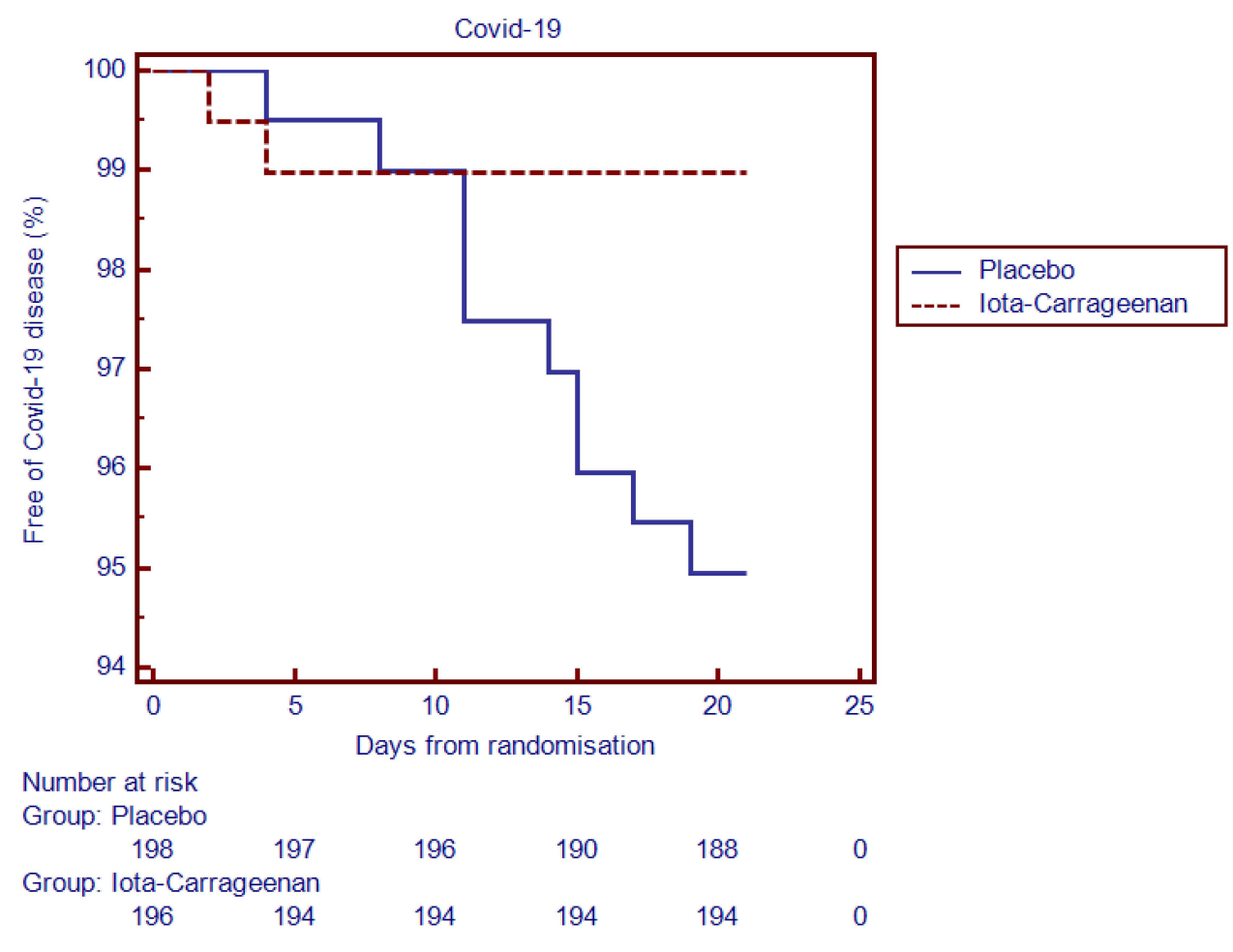

Figure 2 Kaplan-Meier survival plot of COVID-19 disease in the trial participants.

in experimental animals. ${ }^{32}$ These results are particularly relevant since today the only prophylactic interventions with demonstrated efficacy are vaccines yet accessible worldwide. In fact, vaccination rates among healthcare workers remain particularly low, especially in the global south.

There has been growing interest in the potential efficacy of drugs with demonstrated in vitro efficacy. During the early days of COVID-19 pandemic, there was an increased attention to the use of hydroxychloroquine, an agent that was active in vitro but failed to prevent COVID-19 when used as pre or postexposure prophylaxis. ${ }^{27,28}$ With at least two registered clinical trials as of February 2021 (United Kingdom, NCT04590365, and Austria, NCT04681001), Iota-Carrageenan is being proposed as a potential efficacious prophylactic drug. The nasal spray with IotaCarrageenan has already shown clinical efficacy in diseases of the upper airways produced by viruses against which Iota-Carrageenan had demonstrated efficacy in vitro. Additionally, Iota-Carrageenan in vitro efficacy was shown in in vitro concentrations equal to and up to 100 times lower than those estimated to be reached in the nasal cavity with the use of sprays available in different countries with standard dosages. We have recently repeated the in vitro study of the effect of carrageenan spray on SARS-COV-2 infection in Calu-3 cell line observing the same inhibitory effect as in Vero cells (submitted).

The devastating urgency of COVID-19 pandemic requires a simple and pragmatic design trial able to provide, in this context, a quick and efficient answer.

Our study has some limitations. First, we included apparently healthy individuals without confirmation by PCR test. Given that early disease manifested more frequently in the arm with active treatment, we could assume that some people may have been at the end of the incubation period of the disease at the time of their inclusion in this clinical trial. This would contribute to the notion of the prophylactic effect of the I-C spray. Second, those subjects who remained asymptomatic were not tested. PCR or serologic testing for all the participants would have added to the scientific strength of this trial. However, it was not feasible, and an effect on asymptomatic infections cannot be assessed. Our study has also a number of strengths. First, we chose healthcare and other hospital workers to participate in this research as a simple and easy-to-follow model. Second, the number of active principle and placebo administered in each participating center were identical. Third, enrollment took place during high community transmission in Argentina (140.48 cases per 100K inhabitants in July to 173.77 in December, and 1,429,814 total new positive cases 
during the study period $*$ https://iecs.shinyapps.io/covidargentina/). Therefore, our participants were also exposed outside the hospital. Finally, a small number of individuals were lost to follow up (6.8\%).

\section{Conclusions}

Our results suggest that the nasal spray with I-C could give significant protection for COVID-19 prophylaxis in health care workers managing patients with COVID-19 disease. This finding should be replicated in future clinical trials.

\section{Data Sharing Statement}

Data related to this manuscript can be made available from the corresponding author upon reasonable request since the publication.

\section{Acknowledgments}

We thank all participants of the CARR-COV2 research team for their commitment and contributions to this study:

M. Jimena Ortega and Cristina Soler Riera (Hospital Universitario CEMIC, Ciudad Autónoma de Buenos Aires, Argentina), Ana Cajelli (Department of Otolaryngology, Clínica y Maternidad Santa Isabel, Ciudad Autónoma de Buenos Aires, Argentina), Fernando Ross and Mirta Gutiérrez (Department of Medicine, Clínica y Maternidad Santa Isabel, Ciudad Autónoma de Buenos Aires, Argentina), Daniela Federico and Viviana Jalife (Department of Medicine, Hospital Interzonal de Agudos Pte. Perón, Avellaneda, Buenos Aires, Argentina), Mariel Trinidad (Department of Pulmonology, Hospital Interzonal de Agudos Pte. Perón, Avellaneda, Buenos Aires, Argentina), Paula Bellagamba (Department of Pediatrics, Hospital Interzonal de Agudos Pte. Perón, Avellaneda, Buenos Aires, Argentina), Teresa Corallo and Daniel Lamberti (Department of Pulmonology, Hospital Pediátrico Avelino Castelán, Resistencia, Chaco, Argentina), Pablo Oyhamburu, Yael Gonzalez and Carmen Rios (Department of Pulmonology, Hospital Británico de Buenos Aires, Ciudad Autónoma de Buenos Aires, Argentina), Glenda Ernst (Scientific Committee, Hospital Británico de Buenos Aires, Ciudad Autónoma de Buenos Aires, Argentina), Ricardo Reisin (Department of Neurology, Hospital Británico de Buenos Aires, Ciudad Autónoma de Buenos Aires, Argentina), Victor Ikeda (Department of Medicine, Clínica Monte Grande, Monte Grande, Buenos Aires, Argentina), Carolina Osuna (Department of Infectology, Clínica Monte Grande, Monte Grande, Buenos Aires, Argentina), Juan Sang and Natalia Judis (Department of Pulmonology, Hospital 4 de Junio Dr Ramón Carrillo, Saenz
Peña, Chaco, Argentina), Sofía Golé (Department of Family Medicine, Hospital Gral. de Agudos Dr. Teodoro Alvarez, Ciudad Autónoma de Buenos Aires, Argentina) and Lorena Itati Ibañez (Institute of Physical Chemistry of Materials, Environment and Energy (INQUIMAE-CONICET, Buenos Aires University, Buenos Aires, Argentina).

\section{Funding}

The study did not receive any support for hospitals, staff or patients involved. Publication and administrative costs were supported by: Programa de articulación y fortalecimiento federal de las capacidades en ciencia y tecnología COVID-19, Proyecto CABA 20. Ministerio de Ciencia, Tecnología e Innovación, Argentina. Laboratorio Pablo Cassará provided the drug and placebo samples, free of charge.

\section{Disclosure}

Dr Juan Manuel Figueroa report grantfrom Programa de articulación y fortalecimiento federal de las capacidades en ciencia y tecnología COVID-19, Proyecto CABA 20. Ministerio de Ciencia, Tecnología e Innovación, Argentina; Freely provided drug and placebo samples from Laboratorio Pablo Cassará, during the conduct of the study; personal fees from Laboratorio Pablo Cassará, outside the submitted work; Dr Mónica Lombardo report personal fees from Laboratorio Pablo Cassará, outside the submitted work, is a Director of Scientific Affairs at Nobeltri S.R.L; Dr Robert Giugliano report personal fees from Astra Zeneca, personal fees from CVS Caremark, personal fees from Pfizer, personal fees from Novartis, outside the submitted work; and Institutional research grant to the TIMI Study Group at Brigham and Women's Hospital for research he is not directly involved in from Abbott; Aralez; AstraZeneca; Bayer; Eisai; GlaxoSmithKline; Intarcia; Janssen Research and Development; Medicines Company; MedImmune; Novartis; Poxel; Pfizer; Quark Pharmaceuticals; Roche; Takeda; Zora Biosciences. The authors report no other conflicts of interest in this work.

\section{References}

1. Polack FP, Thomas SJ, Kitchin N, et al.; C4591001 Clinical Trial Group. Safety and efficacy of the BNT162b2 mRNA COVID-19 vaccine. $N E n g l$ J Med. 2020;383(27):2603-2615. doi:10.1056/NEJMoa2034577

2. Logunov DY, Dolzhikova IV, Shcheblyakov DV, et al.; GamCOVID-Vac Vaccine Trial Group. Safety and efficacy of an rAd26 and rAd5 vector-based heterologous prime-boost COVID-19 vaccine: an interim analysis of a randomised controlled Phase 3 trial in Russia. Lancet. 2021;397(10275):671-681. doi:10.1016/S01406736(21)00234-8 
3. World Health Organization Draft landscape of COVID-19 candidate vaccines; Jan 22, 2021. Available from: https://www.who.int/publica tions/m/item/draft-landscape-of-cOVID-19-candidate-vaccines. Accessed September 16, 2021.

4. Voysey M, Clemens SAC, Madhi SA. Safety and efficacy of the ChAdOx1 nCoV-19 vaccine (AZD1222) against SARS-CoV-2: an interim analysis of four randomised controlled trials in Brazil, South Africa, and the UK. Lancet. 2021;397:99-111.

5. Baden LR, El Sahly HM, Essink B. Efficacy and safety of the mRNA-1273 SARS-CoV-2 vaccine. $N$ Engl J Med. 2020;384 (5):403-416. doi:10.1056/NEJMoa2035389

6. Zhang C, Zhou D. Adenoviral vector-based strategies against infectious disease and cancer. Hum Vaccin Immunother. 2016;12 (8):2064-2074. doi:10.1080/21645515.2016.1165908

7. Ahmadi A, Zorofchian Moghadamtousi S, Abubakar S, Zandi K. Antiviral potential of algae polysaccharides isolated from marine sources: a review. Biomed Res Int. 2015;2015:825203. PMID 26484353; PMCID: PMC4592888. doi:10.1155/2015/825203

8. Leibbrandt A, Meier C, König-Schuster M, et al. Iota-carrageenan is a potent inhibitor of influenza A virus infection. PLoS One. 2010;5 (12):e14320. doi:10.1371/journal.pone.0014320

9. Wang W, Zhang P, Hao C, Zhang XE, Cui ZQ, Guan HS. In vitro inhibitory effect of carrageenan oligosaccharide on influenza A H1N1 virus. Antiviral Res. 2011;92(2):237-246. doi:10.1016/j.antiviral.20 11.08.010.

10. Grassauer A, Weinmuellner R, Meier C, Pretsch A, PrieschlGrassauer E, Unger H. Iota-Carrageenan is a potent inhibitor of rhinovirus infection. Virol J. 2008;5(1):107. doi:10.1186/1743-42 2X-5-107

11. Grassauer A, Weinmuellner R, Meier C, et al. Interference in dengue virus adsorption and uncoating by carrageenans. Virology. 2007;363 (2):473-485. PMID: 17337028. doi:10.1016/j.virol.2007.01.043

12. Buck CB, Thompson CD, Roberts JN, Müller M, Lowy DR, Schiller JT. Carrageenan is a potent inhibitor of papillomavirus infection. PLoS Pathog. 2006;2(7):e69. PMID: 16839203; PMCID: PMC1500806. doi:10.1371/journal.ppat.0020069

13. Klimyte EM, Smith SE, Oreste P, Lembo D, Dutch RE. Inhibition of human metapneumovirus binding to heparan sulfate blocks infection in human lung cells and airway tissues. $J$ Virol. 2016;90 (20):9237-9250. PMID: 27489270; PMCID: PMC5044844 doi:10.1128/JVI.01362-16

14. Hemilä H, Chalker E. Carrageenan nasal spray may double the rate of recovery from coronavirus and influenza virus infections: re-analysis of randomized trial data. Pharmacol Res Perspect. 2021;9(4):e00810. PMID: 34128358; PMCID: PMC8204093. doi:10.1002/prp2.810

15. Eccles R, Meier C, Jawad M, Weinmüllner R, Grassauer A, PrieschlGrassauer E. Efficacy and safety of an antiviral Iota-Carrageenan nasal spray: a randomized, double-blind, placebo-controlled exploratory study in volunteers with early symptoms of the common cold. Respir Res. 2010;11(1):108. doi:10.1186/1465-9921-11-108

16. Ludwig M, Enzenhofer E, Schneider S, et al. Efficacy of a carrageenan nasal spray in patients with common cold: a randomized controlled trial. Respir Res. 2013;14(1):124. doi:10.1186/1465-9921-14-124

17. Eccles R, Winther B, Johnston SL, Robinson P, Trampisch M, Koelsch S. Efficacy and safety of iota-carrageenan nasal spray versus placebo in early treatment of the common cold in adults: the ICICC trial. Respir Res. 2015;16(1):121. doi:10.1186/s12931-015-0281-8

18. Schütz D, Conzelmann C, Fois G, et al. Carrageenan-containing over-the-counter nasal and oral sprays inhibit SARS-CoV-2 infection of airway epithelial cultures. Am J Physiol Lung Cell Mol Physiol. 2021;320(5):L750-L756. PMID: 33561380. doi: 10.1152/ajplung. 00552.2020
19. Song S, Peng H, Wang Q, et al. Inhibitory activities of marine sulfated polysaccharides against SARS-CoV-2. Food Funct. 2020; 11(9):7415-7420. doi:10.1039/d0fo02017f

20. Morokutti-Kurz M, Graf P, Grassauer A, Prieschl-Grassauer E. SARS-CoV-2 in-vitro neutralization assay reveals inhibition of virus entry by iota-carrageenan. bioRxiv. 2020. doi:10.1101/2020.07. 28.224733

21. Bansal S, Colleen BJ, Taylor SL, et al. Iota-carrageenan and xylitol inhibit SARS-CoV-2 in cell culture. BioRxiv. 2020. doi:10.1101/ 2020.08.19.225854

22. Varese A, Ceballos A, Palacios C, Figueroa JM, Dugour AV. Iotacarrageenan prevents the replication of SARS-CoV-2 on an in vitro respiratory epithelium model. bioRxiv. 2021. doi:10.1101/2021. 04.27 .441512

23. Zou L, Ruan F, Huang M, et al. SARS-CoV-2 viral load in upper respiratory specimens of infected patients. $N$ Engl J Med. 2020;382 (12):1177-1179. PMID: 32074444; PMCID: PMC7121626. doi: 10.1056/NEJMc2001737

24. Graf C, Bernkop-Schnürch A, Egyed A, Koller C, PrieschlGrassauer E, Morokutti-Kurz M. Development of a nasal spray containing xylometazoline hydrochloride and iota-carrageenan for the symptomatic relief of nasal congestion caused by rhinitis and sinusitis. Int $J$ Gen Med. 2018;11:275-283. doi:10.2147/IJGM.S1 67123

25. Lauer SA, Grantz KH, Bi Q, et al. The incubation period of coronavirus disease 2019 (COVID-19) from publicly reported confirmed cases: estimation and application. Ann Intern Med. 2020;172 (9):577-582. PMID: 32150748; PMCID: PMC7081172. doi:10.73 26/M20-0504

26. Xin H, Wong JY, Murphy C, et al. the incubation period distribution of coronavirus disease 2019: a systematic review and meta-analysis. Clin Infect Dis. 2021:ciab501. doi:10.1093/cid/ciab501

27. Boulware DR, Pullen MF, Bangdiwala AS, et al. A randomized trial of hydroxychloroquine as postexposure prophylaxis for covid-19. $N$ Engl J Med. 2020;383(6):517-525. doi:10.1056/ NEJMoa2016638

28. Barnabas RV, Brown ER, Bershteyn A, et al. Hydroxychloroquine as postexposure prophylaxis to prevent severe acute respiratory syndrome coronavirus 2 infection: a randomized trial. Ann Intern Med. 2021;174(3):344-352. doi:10.7326/M20-6519

29. Mitjà O, Corbacho-Monné M, Ubals M, et al.; BCN-PEP-CoV2 research group. A cluster-randomized trial of hydroxychloroquine for prevention of covid-19. N Engl J Med. 2021;384(5):417-427. PMID: 33289973; PMCID: PMC7722693. doi: 10.1056/NEJMoa20 21801

30. Niriella MA, Ediriweera DS, De Silva AP, et al. Hydroxychloroquine for post-exposure prophylaxis of COVID-19 among naval personnel in Sri Lanka: study protocol for a randomized, controlled trial. Trials. 2020;21(1):748. PMID: 32854751; PMCID: PMC7450681. doi:10.11 86/s13063-020-04659-7

31. Griffin DO, Brennan-Rieder D, Ngo B, et al. The importance of understanding the stages of COVID-19 in treatment and trials. AIDS Rev. 2021;23(1):40-47. PMID: 33556957. doi:10.24875/ AIDSRev.200001261

32. Weiner ML. Food additive carrageenan: part II: a critical review of carrageenan in vivo safety studies. Crit Rev Toxicol. 2014;44 (3):244-269. PMID: 24467586. doi:10.3109/10408444.2013.86 1798 


\section{Publish your work in this journal}

The International Journal of General Medicine is an international, peer-reviewed open-access journal that focuses on general and internal medicine, pathogenesis, epidemiology, diagnosis, monitoring and treatment protocols. The journal is characterized by the rapid reporting of reviews, original research and clinical studies across all disease areas. The manuscript management system is completely online and includes a very quick and fair peer-review system, which is all easy to use. Visit http://www.dovepress.com/ testimonials.php to read real quotes from published authors.

Submit your manuscript here: https://www.dovepress.com/international-journal-of-general-medicine-journal 